\title{
Short- and Long-Term Mortality Trends in STEMI-Cardiogenic Shock over Three Decades (1989-2018): The Ruti-STEMI-Shock Registry
}

\author{
Cosme García-García ${ }^{1,2, *(1)}$, Teresa Oliveras ${ }^{1, \dagger}{ }^{\dagger}$, Nabil El Ouaddi ${ }^{1}$, Ferran Rueda ${ }^{1}$, Jordi Serra ${ }^{1}$, \\ Carlos Labata ${ }^{1}$, Marc Ferrer ${ }^{1}$, German Cediel ${ }^{1}$, Santiago Montero ${ }^{1}{ }^{(D,}$, Maria Jose Martínez ${ }^{1}$, \\ Helena Resta ${ }^{1}$, Oriol de Diego ${ }^{1}$, Joan Vila ${ }^{3}$, Irene R Dégano ${ }^{2,3}$, Roberto Elosua ${ }^{2,4,5}$, \\ Josep Lupón 1,2,6 $\mathbb{D}$ and Antoni Bayes-Genis 1,2,6 \\ 1 Heart Institute, Hospital Universitari Germans Trias i Pujol, 08916 Badalona, Spain; \\ 3aoliveras@gmail.com (T.O.); elouaddi@hotmail.com (N.E.O.); fruedasobella@hotmail.com (F.R.); \\ jserra.germanstrias@gencat.cat (J.S.); clabata@hotmail.com (C.L.); mafema1986@hotmail.com (M.F.); \\ gecediel@yahoo.com (G.C.); monteroaradas@gmail.com (S.M.); mj.martinez.membrive@gmail.com (M.J.M.); \\ helena.rs92@gmail.com (H.R.); orioldediego@gmail.com (O.d.D.); jluponroses@gmail.com (J.L.); \\ abayesgenis@gmail.com (A.B.-G.) \\ 2 CIBER Enfermedades Cardiovasculares (CIBERCV), 08080 Madrid, Spain; iroman@imim.es (I.R.D.); \\ relosua@imim.es (R.E.) \\ 3 REGICOR Study Group, IMIM (Institut Hospital del Mar d'Investigacions Mèdiques), 08003 Barcelona, \\ Spain; jvila@imim.es \\ 4 Faculty of Medicine, University of Vic-Central University of Catalonia (UVic-UCC), 08500 Vic, Spain \\ 5 Cardiovascular Epidemiology and Genetics Group, IMIM, 08003 Barcelona, Spain \\ 6 Department of Medicine, Autonomous University of Barcelona, 08916 Barcelona, Spain \\ * Correspondence: cosmecg7@gmail.com; Tel.: +34-9-3497-8662; Fax: +34-9-3497-8939 \\ + PhD Program, Department of Medicine. Autonomous University of Barcelona.
}

Received: 19 June 2020; Accepted: 23 July 2020; Published: 27 July 2020

\begin{abstract}
Aims: Cardiogenic shock (CS) is an ominous complication of ST-elevation myocardial infarction (STEMI), despite the recent widespread use of reperfusion and invasive management. The Ruti-STEMI-Shock registry analysed the prevalence of and 30-day and 1-year mortality rates in ST-elevation myocardial infarction (STEMI) complicated by CS (STEMI-CS) over the last three decades. Methods and Results: From February 1989 to December 2018, 493 STEMI-CS patients were consecutively admitted in a well-defined geographical area of $\sim 850,000$ inhabitants. Patients were classified into six five-year periods based on their year of admission. STEMI-CS mortality trends were analysed at 30 days and 1 year across the six strata. Cox regression analyses were performed for comparisons. Mean age was $67.5 \pm 11.7$ years; $69.4 \%$ were men. STEMI-CS prevalence did not decline from period 1 to 6 (7.1 vs. $6.2 \%, p=0.218)$. Reperfusion therapy increased from $22.5 \%$ in $1989-1993$ to $85.4 \%$ in 2014-2018. Thirty-day all-cause mortality declined from period 1 to $6(65 \% \mathrm{vs}$. $50.5 \%, p<0.001$ ), with a $9 \%$ reduction after multivariable adjustment (HR: $0.91 ; 95 \%$ CI: 0.84-0.99; $p=0.024)$. One-year all-cause mortality declined from period 1 to $6(67.5 \%$ vs. $57.3 \%, p=0.001)$, with an $8 \%$ reduction after multivariable adjustment (HR: $0.92 ; 95 \%$ CI: $0.85-0.99 ; p=0.030$ ). Short- and long-term mortality trends in patients aged $\geq 75$ years remained $\sim 75 \%$. Conclusions: Short- and long-term STEMI-CS-related mortality declined over the last 30 years, to $\sim 50 \%$ of all patients. We have failed to achieve any mortality benefit in STEMI-CS patients over 75 years of age.
\end{abstract}

Keywords: ST-elevation myocardial infarction; prognosis; STEMI complications; STEMI mortality 


\section{Introduction}

Cardiogenic shock (CS) is a low cardiac output state caused by myocardial dysfunction that leads to severe hypoperfusion resulting in life-threatening critical multiorgan failure. CS is the leading cause of hospital mortality associated with acute myocardial infarction (MI). Prevalence of CS due to acute MI varies from 5 to $15 \%$ [1-8], although some of these data come from studies performed before the generalization of reperfusion [1,2]. Despite recent advances in the prevention and management of acute MI, and the widespread use of primary percutaneous coronary intervention in patients with ST-elevation MI (STEMI), acute phase mortality of STEMI-complicated CS (STEMI-CS) remains unacceptably high [6-11]. Data on long-term trends in STEMI-CS prevalence and short- and long-term mortality are scarce. Indeed, most of the reported data reflect either limited trends, rarely beyond a decade, or only in-hospital or short-term evolution [8,9].

Accordingly, the aim of this study was to describe trends in prevalence, management, in-hospital complications, and 30-day and 1-year mortality in STEMI-CS over the last three decades (1989-2018). In addition, it also aimed to address management and prognosis across sex and age, with emphasis in cardiogenic shock patients $\geq 75$ years during the same study period.

\section{Methods and Materials}

\subsection{Study Population}

The Ruti-STEMI-SHOCK registry is a prospective population-based registry maintained from February 1989 to December 2018. It includes all eligible STEMI patients from a well-defined geographical area of $\sim 850,000$ inhabitants in the northern metro area of Barcelona in Catalonia, Spain (Figure 1). During the 30-year period the physical healthcare structure has remained stable, with only one university hospital with an intensive cardiac care unit (ICCU) and four community hospitals that refer STEMI patients to the ICCU (Figure 1). Several organizational changes have occurred during the registry period. Until the year 2000, reperfusion therapy was mainly performed with fibrinolysis and, from 2000 to 2009, primary percutaneous coronary intervention (PCI) was performed only during working hours. A major change in June 2009 was the establishment of the "Codi IAM" STEMI network, intended as a reperfusion network that prioritizes primary PCI (pPCI) for all STEMI patients 24/7. The set-up of the Codi IAM network, including its territorial organization and available resources, has been described previously [12,13].

Definitions of myocardial infarction and the standard of care were based on current guidelines available during the study lifespan [14-17]. STEMI was defined as ST elevation of $\geq 1 \mathrm{~mm}$ in at least two contiguous leads (in V2 and V3 $\geq 2 \mathrm{~mm}$ was required) in any location in the index or qualifying electrocardiogram. Cardiogenic shock was defined as systolic blood pressure $<90 \mathrm{~mm} \mathrm{Hg}$ (after adequate fluid challenge) for $30 \mathrm{~min}$ or a need for vasopressor therapy to maintain systolic blood pressure $>90 \mathrm{~mm} \mathrm{Hg}$, and signs of hypoperfusion (altered mental status/confusion, cold periphery, oliguria $<0.5 \mathrm{~mL} / \mathrm{kg} / \mathrm{h}$ for the previous $6 \mathrm{~h}$, or blood lactate $>2 \mathrm{mmol} / \mathrm{L}$ ) $[1,18]$.

Patients were stratified depending on the year of admission into six five-year periods: 1989-1993 (period 1), 1994-1998 (period 2), 1999-2003 (period 3), 2004-2008 (period 4), 2009-2013 (period 5), and 2014-2018 (period 6).

All study procedures were in accordance with the ethical standards outlined in the Declaration of Helsinki. Patients provided written consent for use of their clinical data for research purposes. 


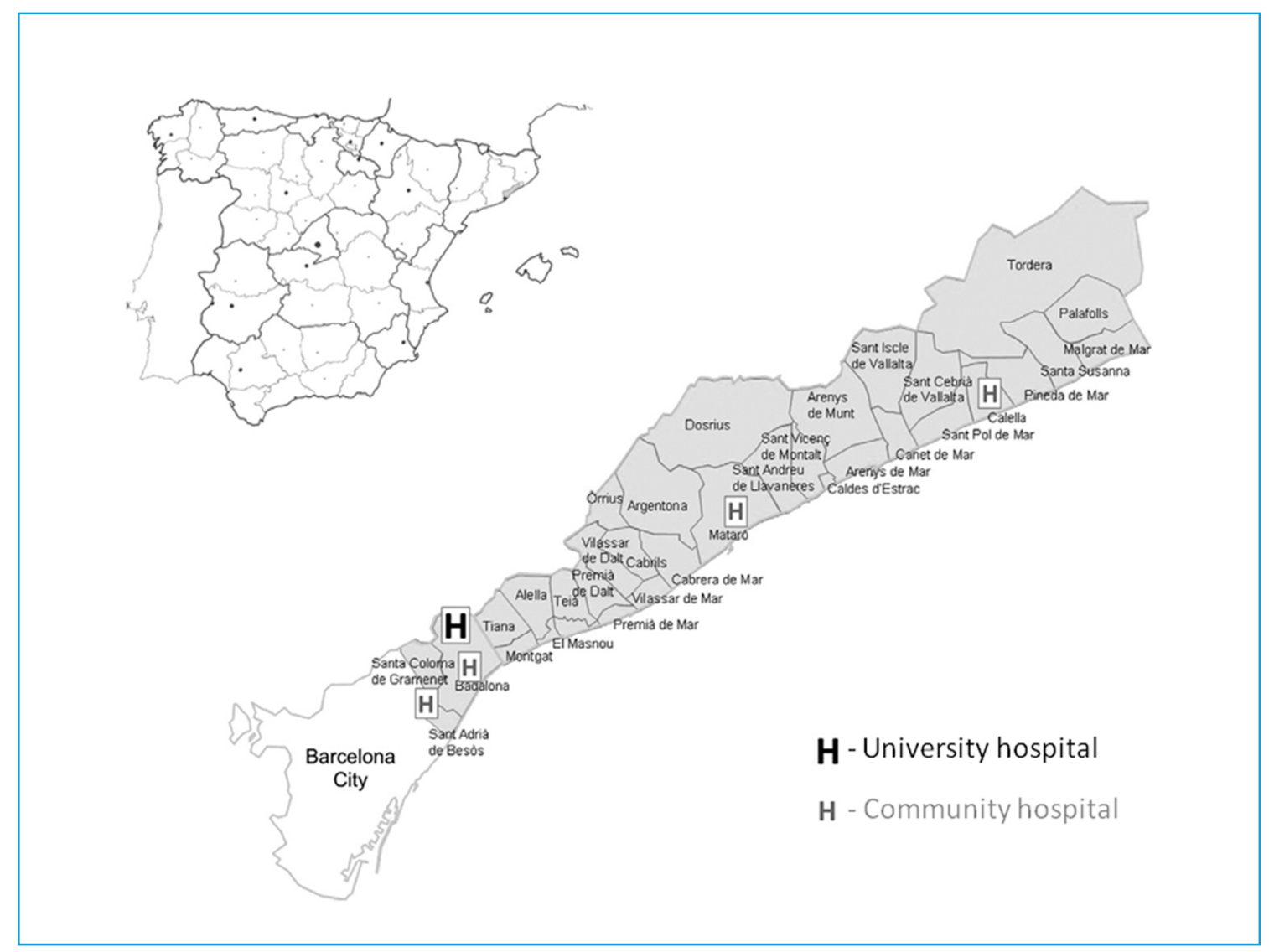

Figure 1. Geographical distribution of the Ruti-STEMI-Shock population-based registry in the northern Barcelona metro area.

\subsection{Outcomes}

The aim of the study was to analyse STEMI-CS trends in 30-day and 1-year case-fatality over the last three decades. Mortality rates were curated from patient health records and/or by direct phone contact with patients or relatives and verified by the Catalan and Spanish health system databases. Thirty-day and 1-year mortality rates for the first period (1989-1993) were incomplete and have not been incorporated in the results. Thirty-day mortality data was complete in $99 \%$ of cardiogenic shock patients and 1-year mortality data was available in $98.2 \%$ of patients.

Secondary endpoints included changes in the most relevant in-hospital STEMI-CS complications during the six studied periods: primary ventricular fibrillation and tachycardia, atrio-ventricular block, atrial fibrillation/flutter, ventricular septum or papillary muscle or free wall rupture, and right ventricle dysfunction. Definitions of these complications have remained stable during the study period. In-hospital complications were adjudicated by two independent physicians. We also analysed trends in the in-hospital management of STEMI-CS patients.

\subsection{Statistical Analysis}

Categorical variables are expressed as frequencies and percentages and continuous variables as means \pm standard deviation (SD). Statistical differences between groups were compared using the Chi-squared and Student's $t$-test, or analysis of variance including linear trend analysis. Departures from normality were evaluated using normal QQ-plots. Multivariate analysis was performed with logistic regression or proportional Cox regression models (Cox), with the following covariates: age, sex, reperfusion, anterior wall MI, and previous MI. Assumptions of the linearity of continuous variables (logistic regression and Cox) and proportionality (Cox) were tested. To assess the discrimination of the 
Cox models, Harrell's C statistics was used; calibration was assessed using the Royston modification of Nagelkerke's R2 statistic test for proportional hazards models. Trend curves were graphically fitted using polynomial regression, as they provide better fits to the nonlinear data. The period of admission was treated as a continuous measure for trend testing. Probability values $<0.05$ from two-sided tests were considered to indicate statistical significance. All analyses were performed using the software IBM Statistics SPSS 21 (Chicago, IL, USA).

\section{Results}

A total of 7984 consecutive patients with STEMI were included during the study period; the mean age was 61.7 years (SD 12.7), and 79.2\% were men. STEMI-CS developed in 493 patients $(6.2 \%$ of all STEMI). Baseline demographic and clinical characteristics between STEMI-CS and non-CS patients are shown in Table 1. Patients who developed STEMI-CS were older than nonCS patients (67.5 vs. 61.3 years, $p<0.001)$ and one-third of them were aged $\geq 75$ years. STEMI-CS patients were more likely to be women (30.6\% vs. $20.2 \%$ ) and more comorbid (hypertension, diabetes, peripheral disease, and previous MI). Reperfusion therapy was less often performed in STEMI-CS (63.9\% vs. $72.8 \%$; $p<0.001)$.

Table 1. Demographic characteristics, management, and prognosis in shock and non-shock STEMI patients.

\begin{tabular}{|c|c|c|c|c|}
\hline Characteristics * & $\begin{array}{l}\text { Whole Cohort } \\
\quad(n=7984)\end{array}$ & $\begin{array}{c}\text { Non-Shock } \\
\text { Patients } \\
(\mathrm{n}=7491)\end{array}$ & $\begin{array}{l}\text { Shock Patients } \\
\qquad(\mathrm{n}=493)\end{array}$ & $p$ for Trend \\
\hline Age, years: mean, (SD) & $61.8(12.6)$ & $61.3(12.6)$ & $67.5(11.7)$ & $<0.001$ \\
\hline Age $>75$ years, $\%$ & 17.2 & 16.3 & 31.4 & $<0.001$ \\
\hline Women, \% & 20.8 & 20.2 & 30.6 & $<0.001$ \\
\hline Smoker, \% & 43.4 & 44.0 & 33.1 & $<0.001$ \\
\hline Hypertension, \% & 51.2 & 50.7 & 58.0 & 0.007 \\
\hline Dyslipidaemia, \% & 51.8 & 52.3 & 43.8 & $<0.001$ \\
\hline Diabetes Mellitus, \% & 26.3 & 25.8 & 38.1 & $<0.001$ \\
\hline Peripheral Disease, $\%$ & 9.7 & 9.4 & 15.2 & $<0.001$ \\
\hline Previous MI, \% & 14.7 & 14.4 & 19.3 & 0.003 \\
\hline Anterior Wall AMI, \% & 44.4 & 43.8 & 51.3 & 0.005 \\
\hline Reperfusion, \% & 72.2 & 72.8 & 63.9 & 0.001 \\
\hline Fibrinolysis, $\%$ & 31.3 & 31.2 & 31.5 & 0.696 \\
\hline Primary PCI, \% & 68.7 & 68.8 & 68.5 & 0.875 \\
\hline Coronary Angiography, \% & 56.1 & 56.3 & 52.6 & 0.307 \\
\hline Re-infarction, $\%$ & 1.8 & 1.5 & 4.9 & $<0.001$ \\
\hline Atrial Fibrillation, $\%$ & 7.9 & 6.9 & 22.1 & $<0.001$ \\
\hline Sustained VT, \% & 5.9 & 4.7 & 23.3 & $<0.001$ \\
\hline Primary VF, \% & 6.8 & 5.6 & 25.2 & $<0.001$ \\
\hline Complete AV Block * \% & 11.9 & 10.3 & 39.1 & $<0.001$ \\
\hline Right Ventric. $\mathrm{MI} *, \%$ & 11.4 & 9.2 & 50.6 & $<0.001$ \\
\hline FWR, \% & 1.2 & 0.9 & 6.5 & $<0.001$ \\
\hline PMR, \% & 0.4 & 0.2 & 3.2 & $<0.001$ \\
\hline VSR, \% & 0.7 & 0.2 & 7.1 & $<0.001$ \\
\hline ICCU LoS, days (SD) & $3.7(3.7)$ & $3.5(3.3)$ & $5.0(7.5)$ & $<0.001$ \\
\hline ICCU mortality, \% & 5.5 & 2.2 & 52.6 & $<0.001$ \\
\hline 30-day mortality, \% & 6.9 & 3.3 & 61.3 & $<0.001$ \\
\hline 1-year mortality, \% & 9.4 & 5.6 & 66.5 & $<0.001$ \\
\hline
\end{tabular}

ICCU, intensive cardiovascular care unit; AMI, acute myocardial infarction; LoS, length of stay; ${ }^{*}$ only considering inferior wall AMI; VF, ventricular fibrillation; VT, ventricular tachycardia; FWR, free wall rupture; PMR, papillary muscle rupture; VSR, ventricular septal rupture.

Acute phase intensive cardiac care unit (ICCU) mortality was 52.6\% in STEMI-CS compared to $2.2 \%$ in nonCS patients $(p<0.001)$. Similar trends were observed for 30 -day $(61.3 \%$ vs. $3.3 \% ; p<0.001)$ and one-year mortality $(66.5 \%$ vs. $5.6 \% ; p<0.001)$. 
Relative to the year of admission, STEMI-CS patients were grouped into the six five-year periods defined above: 1989-1993, $\mathrm{n}=80 ; 1994-1998, \mathrm{n}=68 ; 1999-2003, \mathrm{n}=49 ;$ 2004-2008, $\mathrm{n}=91 ;$ 2009-2013, $\mathrm{n}=102$, and 2014-2018, $\mathrm{n}=103$ patients. STEMI-CS prevalence trended to decline by $13 \%$ between 1989-1993 and 2014-2018 (7.1\% vs. 6.2\%, $p=0.218)$. Table 2 shows STEMI-CS prevalence trends relative to sex across the six temporal strata.

Table 2. Demographic characteristics and management of STEMI-CS patients across the six studied periods.

\begin{tabular}{|c|c|c|c|c|c|c|c|}
\hline & $\begin{array}{c}\text { Period 1 } \\
1989-1993 \\
(\mathrm{~N}=80)\end{array}$ & $\begin{array}{c}\text { Period } 2 \\
1994-1998 \\
(\mathrm{~N}=68)\end{array}$ & $\begin{array}{c}\text { Period } 3 \\
1999-2003 \\
(\mathrm{~N}=49)\end{array}$ & $\begin{array}{c}\text { Period } 4 \\
2004-2008 \\
(\mathrm{~N}=91)\end{array}$ & $\begin{array}{c}\text { Period } 5 \\
2009-2013 \\
(N=102)\end{array}$ & $\begin{array}{c}\text { Period } 6 \\
2014-2018 \\
(N=103)\end{array}$ & $\begin{array}{l}p \text { for } \\
\text { Trend }\end{array}$ \\
\hline Age, years, -mean, (SD) & $62.4(12.0)$ & $68.5(11.4)$ & $67.2(10.7)$ & $67.4(11.7)$ & $70.6(11.1)$ & $67.6(11.8)$ & 0.001 \\
\hline Elderly ( $\geq 75$ years) & 15.7 & 25.8 & 26.5 & 34.4 & 44.0 & 33.0 & 0.004 \\
\hline Women, \% & 26.3 & 38.3 & 34.7 & 30.8 & 31.4 & 26.0 & 0.560 \\
\hline Smoker, \% & 41.3 & 27.9 & 36.7 & 29.1 & 24.5 & 39.8 & $<0.001$ \\
\hline Hypertension, \% & 50.0 & 51.5 & 49.0 & 63.7 & 62.7 & 63.1 & 0.145 \\
\hline Dyslipidaemia, \% & 32.5 & 23.5 & 22.4 & 46.2 & 58.8 & 59.2 & $<0.001$ \\
\hline Diabetes mellitus, $\%$ & 31.3 & 38.2 & 44.9 & 42.9 & 42.2 & 32.0 & 0.332 \\
\hline Peripheral disease, $\%$ & 21.3 & 13.2 & 20.0 & 23.1 & 15.7 & 10.7 & 0.043 \\
\hline Previous AMI & 30.0 & 29.4 & 24.5 & 16.5 & 13.7 & 9.7 & 0.001 \\
\hline Anterior Wall AMI & 52.5 & 51.5 & 49.0 & 50.5 & 51.0 & 52.4 & 0.031 \\
\hline Prevalence of CS & 7.1 & 7.0 & 5.0 & 6.4 & 5.6 & 6.2 & 0.218 \\
\hline Men & 6.6 & 5.4 & 4.0 & 5.6 & 4.9 & 5.8 & 0.552 \\
\hline Women & 8.9 & 12.8 & 9.6 & 9.3 & 8.2 & 7.6 & 0.147 \\
\hline Reperfusion, \% & 22.5 & 44.1 & 65.3 & 72.5 & 79.4 & 85.4 & $<0.001$ \\
\hline Fibrinolysis, \% & 100 & 100 & 60.6 & 36.3 & 0 & 0 & \\
\hline Primary PCI, \% & 0 & 0 & 39.4 & 67.7 & 100 & 100 & \\
\hline Time onset-reperfusion * & - & - & $275(623)$ & $252(256)$ & $253(302)$ & 185 (127) & 0.027 \\
\hline \multirow[t]{2}{*}{ Coronary angiography } & 0.0 & 1.5 & 24.5 & 50.5 & 80.4 & 85.4 & $<0.001$ \\
\hline & $\begin{array}{c}\text { Period 1 } \\
1989-1993 \\
(\mathrm{~N}=80) \\
\end{array}$ & $\begin{array}{c}\text { Period } 2 \\
1994-1998 \\
(\mathrm{~N}=68)\end{array}$ & $\begin{array}{c}\text { Period } 3 \\
1999-2003 \\
(\mathrm{~N}=49)\end{array}$ & $\begin{array}{c}\text { Period } 4 \\
2004-2008 \\
(\mathrm{~N}=91)\end{array}$ & $\begin{array}{c}\text { Period } 5 \\
2009-2013 \\
(N=102)\end{array}$ & $\begin{array}{c}\text { Period } 6 \\
2014-2018 \\
(N=103) \\
\end{array}$ & $\begin{array}{l}p \text { for } \\
\text { Trend }\end{array}$ \\
\hline \multicolumn{8}{|l|}{ In-Hospital Management } \\
\hline Aspirin, $\%$ & 65.0 & 63.2 & 83.7 & 83.5 & 97.6 & 96.9 & $<0.001$ \\
\hline Clopidogrel, \% & - & - & 10.2 & 50.5 & 58.8 & 69.9 & $<0.001$ \\
\hline Ticagrelor, \% & - & - & - & - & 0.0 & 4.9 & $<0.001$ \\
\hline Prasugrel, $\%$ & - & - & 一 & - & 1.0 & 23.3 & $<0.001$ \\
\hline IIb/IIIa inhibitors \% & - & - & 6.1 & 27.5 & 21.6 & 12.7 & $<0.001$ \\
\hline Heparin, \% & 47.5 & 38.2 & 69.4 & 78.0 & 58.8 & 64.1 & $<0.001$ \\
\hline $\begin{array}{l}\text { Low-molecular weight } \\
\text { heparin, } \%\end{array}$ & 11.3 & 16.2 & 22.4 & 24.2 & 21.6 & 37.9 & $<0.001$ \\
\hline Statins, $\%$ & 2.5 & 2.1 & 2.0 & 28.6 & 35.3 & 71.8 & $<0.001$ \\
\hline Inotropes, \% & 86.3 & 89.7 & 93.9 & 92.3 & 92.5 & 93.2 & $<0.001$ \\
\hline Invasive Mec. Ventilation, \% & 47.5 & 58.8 & 61.2 & 64.8 & 49.0 & 48.5 & 0.088 \\
\hline $\begin{array}{l}\text { Non Invasive Mec. } \\
\text { Ventilation, \% }\end{array}$ & - & - & - & - & 2.0 & 14.6 & $<0.001$ \\
\hline $\mathrm{IABP}, \%$ & - & - & 12.2 & 35.2 & 38.2 & 35.9 & $<0.001$ \\
\hline $\begin{array}{l}\text { Ventricular support device } \\
\text { (Impella CP), \% }\end{array}$ & - & - & - & - & - & 9.7 & - \\
\hline Mild Hypothermia, \% & - & - & - & - & - & 11.7 & - \\
\hline Pulmonary artery catheter, $\%$ & 37.5 & 38.2 & 36.7 & 23.1 & 12.7 & 32.0 & $<0.001$ \\
\hline
\end{tabular}

\subsection{STEMI-CS Characteristics and Management during the Last 30 Years}

STEMI-CS demographic characteristics and management over the six studied periods are shown in Table 2. Compared with 1989-1993, STEMI-CS patients included in 2014-2018 were older (67.6 vs. 62.4 years; $p=0.001$ ) and had more history of dyslipidaemia and hypertension, but less peripheral arterial disease or previous MI $(9.7 \%$ vs. $30 \%, p=0.001)$. 
Reperfusion therapy increased four-fold from $1989-1993$ to $2014-2018$ (22.5\% vs. $85.4 \% ; p<0.001)$; with remarkably different strategies over time. From 1989-1999, reperfusion was exclusively done with i.v. thrombolytics; from 2000-2009 thrombolysis and pPCI coexisted, and from 2010-2018, since the set-up of the Codi-IAM STEMI network, all patients were treated with pPCI. The use of aspirin, clopidogrel, and other antithrombotic agents, as well as statins, increased markedly over time, as did the use of inotropes (Table 2).

Mechanical ventilation did not differ significantly between periods, and noninvasive ventilation was added in the last decade as an alternative for some patients. The use of haemodynamic support for STEMI-CS patients has evolved over time, and in the period 2014-2018 an intra-aortic balloon pump was used in 35\% and ventricular assist devices in $9.7 \%$ of patients. Cardiac surgery was performed in $6.1 \%$ of patients.

Medical therapies and invasive procedures have been analysed between patients older and younger than 75 years and there were no significant differences in the use of aspirin, antithrombotic therapies, statins, reperfusion therapies, IABP implantation, ventricular assistant devices, or coronary angiography. The use of mechanical ventilation was higher in patients aged over 75 (55\% vs. $36.9 \%$, $p<0.001)$.

\subsection{STEMI-CS in-Hospital Complications Trends}

Supplementary Table S1 shows in-hospital CS-STEMI complications. Ventricular malignant arrhythmias (primary ventricular fibrillation or tachycardia) developed in more than $50 \%$ of STEMI-CS patients, without significant changes over time; supraventricular tachyarrhythmias increased over time. No significant differences in mechanical complications or right ventricular dysfunction were observed in the 30-year period (Table S1), although the limited sample size of these infrequent complications could reduce the value of these results.

\subsection{STEMI-CS 30-Day and 1-Year Mortality Trends}

STEMI-CS 30-day mortality declined from period 2 to period $6(80.9 \%$ vs. $50.5 \%, p<0.001)$ (Table 3; Figure 2), with a 9\% reduction after multivariable adjustment (HR: 0.91 ; 95\% CI: 0.84-0.99; $p=0.024$ ) (Table 4). This model had a Harrell's C statistic of 0.733 (95\% CI: 0.712-0.754) and the Royston modification of Nagelkerke's R2 statistic test showed an appropriate goodness-of-fit of the model (R2 0.26).

Table 3. Acute phase, 30-day case-fatality and 1-year all-cause mortality relative to strata, sex and age.

\begin{tabular}{|c|c|c|c|c|c|c|c|}
\hline & $\begin{array}{c}\text { Period 1 } \\
1989-1993 \\
(\mathrm{~N}=80)\end{array}$ & $\begin{array}{c}\text { Period } 2 \\
1994-1998 \\
(N=68)\end{array}$ & $\begin{array}{c}\text { Period } 3 \\
1999-2003 \\
(N=49)\end{array}$ & $\begin{array}{c}\text { Period } 4 \\
2004-2008 \\
(N=91)\end{array}$ & $\begin{array}{c}\text { Period } 5 \\
2009-2013 \\
(N=102)\end{array}$ & $\begin{array}{c}\text { Period } 6 \\
2014-2018 \\
(N=103)\end{array}$ & $\begin{array}{l}p \text { for } \\
\text { Trend }\end{array}$ \\
\hline ICCU mortality, \% & 61.3 & 76.5 & 59.2 & 53.8 & 52.0 & 43.7 & 0.001 \\
\hline Men & 59.3 & 71.4 & 62.5 & 50.8 & 50.0 & 43.4 & 0.054 \\
\hline Women & 66.7 & 84.6 & 52.9 & 60.7 & 56.3 & 44.3 & 0.068 \\
\hline Young ( $<75$ years) & 62.7 & 69.6 & 50.0 & 44.1 & 37.5 & 33.3 & $<0.001$ \\
\hline Elderly ( $\geq 75$ years) & 54.5 & 87.5 & 84.6 & 74.2 & 70.5 & 64.7 & 0.348 \\
\hline 30-day case-fatality, \% & NA & 80.9 & 63.3 & 56.0 & 59.8 & 50.5 & $<0.001$ \\
\hline Men & NA & 76.2 & 68.8 & 50.8 & 57.1 & 50.0 & 0.006 \\
\hline Women & NA & 88.5 & 52.9 & 67.9 & 65. & 51.9 & 0.024 \\
\hline Young ( $<75$ years) & NA & 73.9 & 52.8 & 45.8 & 44.6 & 39.1 & $<0.001$ \\
\hline Elderly ( $\geq 75$ years) & NA & 93.8 & 92.3 & 74.2 & 79.5 & 73.5 & 0.085 \\
\hline 1-year mortality, \% & NA & 85.3 & 65.3 & 68.1 & 61.8 & 57.3 & $<0.001$ \\
\hline Men & NA & 83.3 & 68.8 & 61.9 & 58.6 & 56.6 & 0.004 \\
\hline Women & NA & 88.5 & 58.8 & 82.1 & 68.8 & 59.3 & 0.048 \\
\hline Young ( $<75$ years) & NA & 80.4 & 55.6 & 59.3 & 46.4 & 44.9 & $<0.001$ \\
\hline Elderly ( $\geq 75$ years) & NA & 93.8 & 92.3 & 83.9 & 81.8 & 82.4 & 0.208 \\
\hline
\end{tabular}




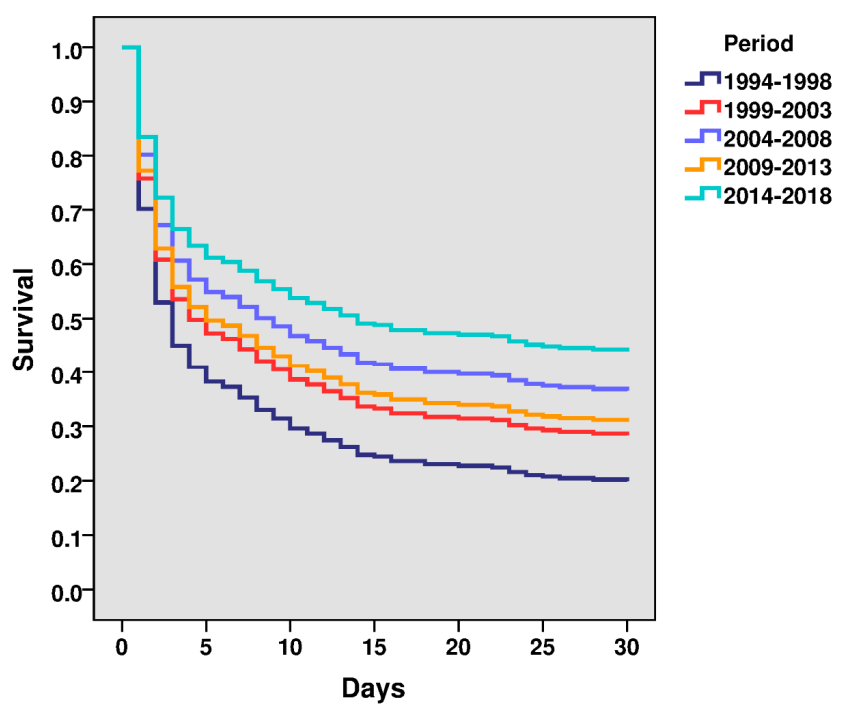

Figure 2. Thirty-day Cox regression multivariate analyses.

Table 4. Multivariable Cox regression analyses for ICCU mortality, 30-day case fatality and 1-year all-cause mortality.

\begin{tabular}{cccccccc}
\hline & $\begin{array}{c}\text { ICCU Mortality } \\
\text { OR (95\% CI) }\end{array}$ & $\boldsymbol{p}$ & $\begin{array}{c}\text { 30-Day } \\
\text { Mortality HR } \\
\mathbf{( 9 5 \% ~ C I ) ~}\end{array}$ & $\boldsymbol{p}$ & $\begin{array}{c}\text { 1-Year Mortality } \\
\text { HR (95\% CI) }\end{array}$ & $p$ \\
\hline Study Period & $0.83(0.73-0.95)$ & 0.005 & $0.91(0.84-0.99)$ & 0.024 & $0.92(0.85-0.99)$ & 0.030 \\
Age & $1.05(1.03-1.07)$ & $<0.001$ & $1.03(1.02-1.05)$ & $<0.001$ & $1.03(1.02-1.04)$ & $<0.001$ \\
Sex & $0.98(0.63-1.51)$ & 0.914 & $0.99(0.77-1.28)$ & 0.968 & $1.03(0.81-1.32)$ & 0.811 \\
Reperfusion & $0.59(0.38-0.93)$ & 0.024 & $0.76(0.58-1.00)$ & 0.052 & $0.78(0.60-1.02)$ & 0.070 \\
Anterior Wall MI & $0.95(0.65-1.40)$ & 0.794 & $0.93(0.74-1.18)$ & 0.570 & $0.93(0.74-1.16)$ & 0.526 \\
Prior MI & $1.09(0.65-1.81)$ & 0.747 & $0.99(0.74-1.33)$ & 0.961 & $1.00(0.76-1.33)$ & 0.966 \\
\hline
\end{tabular}

ICCU, intensive cardiovascular care unit; HR, hazard ratio; MI, myocardial infarction.

STEMI-CS one-year all-cause mortality declined from period 1 to period $6(85.3 \%$ vs. $57.3 \%$, $p=0.007$ ) (Table 3; Figure 3), with an 8\% reduction after multivariable adjustment (HR: 0.92; 95\% CI: $0.85-0.99 ; p=0.030$ ) (Table 4). This model had a Harrell's C statistic of 0.733 (95\% CI: 0.715-0.751) and also exhibited an appropriate goodness-of-fit (Nagelkerke's R2 0.26).

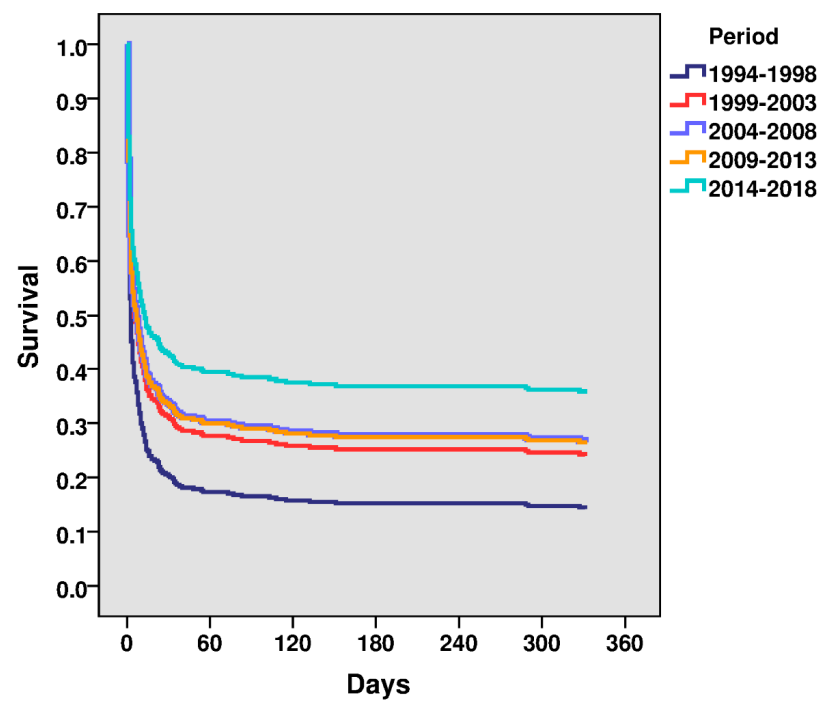

Figure 3. One-year Cox regression multivariate analyses. 
No differences in mortality between men and women were observed in recent years. Short- and long-term mortality in patients aged $\geq 75$ years remained $\sim 75 \%$, without significant changes over time.

\section{Discussion}

The data reported here from the Ruti-STEMI-Shock registry provide long-term longitudinal trends on prevalence, management, and short- and long-term mortality in STEMI-CS in a Mediterranean cohort representing an area of 850,000 inhabitants over the last 30 years. Prevalence of STEMI-CS remains $\sim 6.2 \%$ of all STEMIs. Reperfusion therapies and invasive procedures increased notably over time. Despite the fact that 30-day case-fatality declined by $9 \%$ in adjusted models, it remains $\sim 50 \%$ in the current primary PCI era, without sex differences. Of note, four of five older patients with STEMI-CS, particularly those over 75 years of age, die between 30 days and one year, and this has not changed in the last three decades (Figure 4).

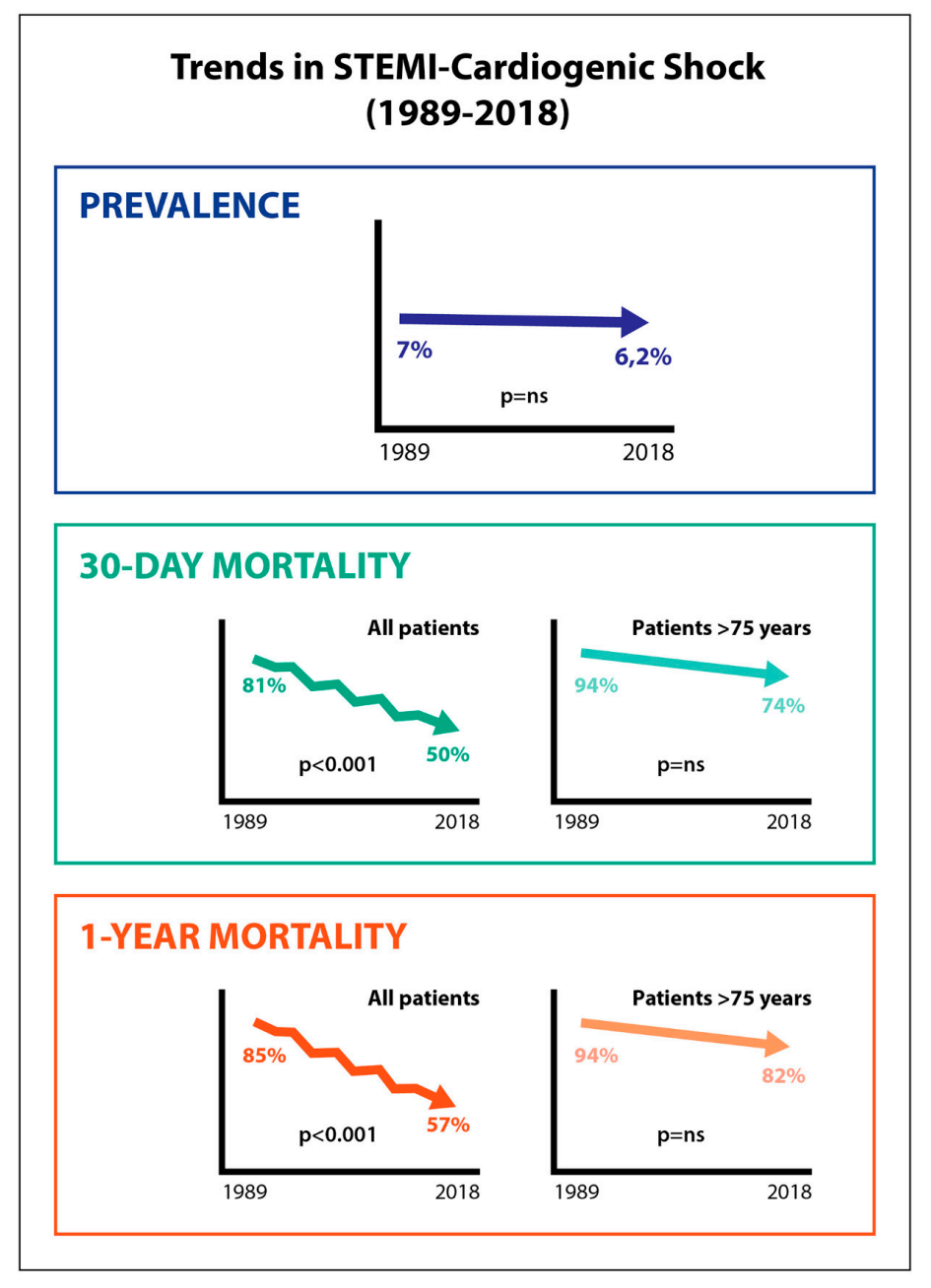

Figure 4. Summary illustration.

CS prevalence is variable in different series, ranging from 5\% to $15 \%$ [1-7]. This reflects the lack of uniform inclusion criteria in the reported registries. Whereas the Ruti-STEMI-Shock registry included only STEMI-CS patients, CS of nonSTEMI origin were also included in French [5] and Italian [10] registries. Furthermore, patients with other aetiologies of CS in addition to acute coronary syndrome were included in a French registry [7] and in the CardShock study [6]. Considering only STEMI-CS, as in the data we report here, similar prevalence $(6.6 \%)$ was observed in a recent Danish cohort study [19]. 
CS prevalence trends are also controversial $[2,7,10,19]$. In our series, CS trended to decline by $13 \%$ over three decades, similar to the results of the Worcester registry [2] and Swedish STEMI registry [3]. Indeed, in our population, CS developed in $6.2 \%$ of STEMI patients in the latest (2014-2018) period, much like the findings reported from Northern Europe in the Swedish STEMI registry [3] and Danish study [19].

Relative to management and in-hospital STEMI-CS complications, important changes happened over the past three decades, the most important being the almost universal use of reperfusion with pPCI. In the most recent period (2014-2018), reperfusion was performed in $>85 \%$ of patients. This value is higher than those reported in the French registry (63\%) in 2005 [5] and similar to those from the Italian study (83\%) [10] in 2014. Both coronary revascularization procedures and the availability of an intensive cardiac care unit have been associated with lower mortality rates [8], although benefits in survival with the use of hemodynamic support devices (i.e., an intra-aortic balloon pump [11] or Impella support $[20,21]$ ) are as yet inconclusive. Furthermore, despite proper reperfusion, no differences in mechanical complications or ventricular arrhythmias were observed over the last 30 years. A potential explanation for the unchanging prevalence of primary VF may be that this arrhythmia occurs primarily ( $75 \%$ of cases in our setting) out of hospital, before any reperfusion therapy is in place [22].

STEMI-CS crude and adjusted 30-day case-fatality declined over the last 30 years. Compared with the second period (1994-1998), in 2014-2018 we observed a 38\% unadjusted relative reduction in 30-day mortality rates (from $80.9 \%$ to $50.5 \%$ ). Substantially higher was the $50 \% 30$-day mortality rate reduction shown in the Danish registry in 2017 [19]. The decline in acute phase mortality we observed was slightly more pronounced in women than in men, indicating the end of sex differences in CS-STEMI prognosis in the modern era and confirming data from other contemporary AMI registries [23]. After multivariable adjustment, 30-day case-fatality for STEMI-CS remained significant, with a 9\% reduction; this improvement was mainly observed in patients younger than 75 years (a nearly $40 \%$ relative reduction in 30-day mortality). Remarkably, short-term mortality in patients aged over 75 years remained above $79 \%$ in all periods, without significant changes over time. Similar results were reproduced at one year, with an $8 \%$ adjusted decline over time and a 33\% relative unadjusted decline (from $85.3 \%$ to $57.3 \%$ ).

The modest achievements obtained in the past three decades do not invite complacency; outcome differences between STEMI-CS and nonCS are appalling. STEMI-CS prognosis, both shortand long-term, remains overwhelmingly poor. Different shock scores have been purposed to assess CS prognosis, the most robust being the CardShock [6] and IABP-Shock II risk scores [24] which have been validated in real-world cardiogenic shock patients [25]. These scores combine classical clinical variables (age, previous AMI or stroke, ejection fraction, and aetiology of shock) with routine biochemical data (glucose, blood lactate, and renal function). Contemporary research on the CS proteome has identified a four-protein score, the CS4P, which has shown additional value above and beyond conventional CardShock or IABP-Shock II risk scores [26]. Transcriptomics and other -omics data are under intense scrutiny to support the identification of high- vs. low-risk patients $[27,28]$, but there is still a long way to go.

This study is not without limitations, but it has the strength of its prospective population-based registry. We acknowledge that a historical cohort study covering three decades implies changes in some definitions of cardiovascular risk factors (diabetes, hypertension, and hypercholesterolaemia) which may have affected their prevalence across periods. The definitions of myocardial infarction and cardiogenic shock have also changed slightly over time. Nevertheless, the essential diagnostic criteria for shock and STEMI remained without significant changes over the study period. On the other hand, information about bleeding, acute kidney injury, or circumstances about cardiac arrest are only available since the last period and were not included. 


\section{Conclusions}

Short- and long-term STEMI-CS mortality declined over the last 30 years, but still affect $\sim 50 \%$ of all patients. We have failed to achieve any mortality benefit in STEMI-CS in patients older than 75 years, with mortality rates close to $80 \%$. New strategies to improve CS prognosis that apply alternative thinking and better characterization of STEMI-CS pathobiology are urgently needed.

Supplementary Materials: The following are available online at http://www.mdpi.com/2077-0383/9/8/2398/s1, Table S1: In-hospital complications.

Author Contributions: Conceptualization, C.G.-G., T.O., S.M., R.E., J.L. and A.B.-G.; Data curation, F.R., J.S., C.L., M.F., G.C., S.M., M.J.M., H.R. and O.d.D.; Formal analysis, G.C., J.V., I.R.D. and J.L.; Investigation, C.L.; Methodology, J.V.; Supervision, F.R., J.L. and A.B.-G.; Validation, N.E.O., J.S., C.L., S.M., M.J.M., O.d.D., J.V., I.R.D., R.E. and A.B.-G.; Visualization, N.E.O., M.F. and H.R.; Writing - original draft, C.G.-G.; Writing - review \& editing, C.G.-G., T.O., J.L. and A.B.-G. All authors have read and agreed to the published version of the manuscript.

Funding: This research received no external funding.

Acknowledgments: The authors thank Antoni Curós and Jordi Serra for their vision and perseverance in data collection and their invaluable clinical work during these three decades. The authors also thank Susanna Tello, Marta Cabañero, and Leny Franco (from Institut Hospital del Mar d'Investigacions Mèdiques), and Sandra Rios and Pilar Gomariz (from Germans Trias Hospital) for their roles in data management and performing database maintenance. We also express special gratitude to all the doctors, residents, and nurses who participated in the Ruti-STEMI registry over the past three decades.

Conflicts of Interest: The authors declare no conflict of interest.

\section{References}

1. Hochman, J.S.; Buller, C.E.; Sleeper, L.A.; Boland, J.; Dzavik, V.; Sanborn, T.A.; Godfrey, E.; White, H.D.; Lim, J.; LeJemtel, T. Cardiogenic shock complicating acute myocardial infarction-etiologies, management and outcome: A report from the SHOCK Trial Registry. SHould we emergently revascularize Occluded Coronaries for cardiogenic shocK. J. Am. Coll. Cardiol. 2000, 36, 1063-1070. [CrossRef]

2. Goldberg, R.J.; Spencer, F.A.; Gore, J.M.; Lessard, D.; Yarzebski, J. Thirty-year trends (1975 to 2005) in the magnitude of, management of, and hospital death rates associated with cardiogenic shock in patients with acute myocardial infarction: A population-based perspective. Circulation 2009, 119, 1211-1219. [CrossRef] [PubMed]

3. Redfors, B.; Angerås, O.; Råmunddal, T.; Dworeck, C.; Haraldsson, I.; Ioanes, D.; Petursson, P.; Libungan, B.; Odenstedt, J.; Stewart, J.; et al. 17-year trends in incidence and prognosis of cardiogenic shock in patients with acute myocardial infarction in western Sweden. Int. J. Cardiol. 2015, 185, 256-262. [CrossRef] [PubMed]

4. Goldberg, R.J.; Makam, R.C.; Yarzebski, J.; McManus, D.D.; Lessard, D.; Gore, J.M. Decade long trends (2001-2011) in the incidence and hospital death rates associated with the in-hospital development of cardiogenic shock after acute myocardial infarction. Circ. Cardiovasc. Qual. Outcomes 2016, 9, 117-125. [CrossRef] [PubMed]

5. Aissaoui, N.; Puymirat, E.; Tabone, X.; Charbonnier, B.; Schiele, F.; Lefèvre, T.; Durand, E.; Blanchard, D.; Simon, T.; Cambou, J.P.; et al. Improved outcome of cardiogenic shock at the acute stage of myocardial infarction: A report from the USIK 1995, USIC 2000, and FAST-MI French nationwide registries. Eur. Heart J. 2012, 33, 2535-2543. [CrossRef] [PubMed]

6. Harjola, V.P.; Lassus, J.; Sionis, A.; Køber, L.; Tarvasmäki, T.; Spinar, J.; Parissis, J.; Banaszewski, M.; Silva-Cardoso, J.; Carubelli, V.; et al. Clinical picture and risk prediction of short-term mortality in cardiogenic shock. Eur. J. Heart Fail. 2015, 17, 501-509, Erratum in 2015, 17, 984. [CrossRef]

7. Puymirat, E.; Fagon, J.Y.; Aegerter, P.; Diehl, J.L.; Monnier, A.; Hauw-Berlemont, C.; Boissier, F; Chatellier, G.; Guidet, B.; Danchin, N.; et al. Cardiogenic shock in intensive care units: Evolution of prevalence, patient profile, management and outcomes, 1997-2012. Eur. J. Heart Fail. 2017, 19, 192-200. [CrossRef]

8. Sánchez-Salado, J.C.; Burgos, V.; Ariza-Solé, A.; Sionis, A.; Canteli, A.; Bernal, J.L.; Fernández, C.; Castrillo, C.; Ruiz-Lera, M.; López-de-Sá, E.; et al. Trends in cardiogenic shock management and prognostic impact of type of treating center. Rev. Esp. Cardiol. (Engl. Ed.) 2019, 73, 546-553. [CrossRef] 
9. Mebazaa, A.; Combes, A.; van Diepen, S.; Hollinger, A.; Katz, J.N.; Landoni, G.; Hajjar, L.A.; Lassus, J.; Lebreton, G.; Montalescot, G.; et al. Management of cardiogenic shock complicating myocardial infarction. Intensive Care Med. 2018, 44, 760-773. [CrossRef]

10. De Luca, L.; Olivari, Z.; Farina, A.; Gonzini, L.; Lucci, D.; Di Chiara, A.; Casella, G.; Chiarella, F.; Boccanelli, A.; Di Pasquale, G.; et al. Temporal trends in the epidemiology, management, and outcome of patients with cardiogenic shock complicating acute coronary syndromes. Eur. J. Heart Fail. 2015, 17, 1124-1132. [CrossRef]

11. Thiele, H.; Zeymer, U.; Neumann, F.J.; Ferenc, M.; Olbrich, H.G.; Hausleiter, J.; Richardt, G.; Hennersdorf, M.; Empen, K.; Fuernau, G.; et al. Intraaortic balloon support for myocardial infarction with cardiogenic shock. N. Engl. J Med. 2012, 367, 1287-1296. [CrossRef] [PubMed]

12. Bosch, X.; Curós, A.; Argimon, J.M.; Faixedas, M.; Figueras, J.; Jiménez-Fàbrega, F.X.; Masià, R.; Mauri, J.; Tresserras, R. Model of primary percutaneous intervention in Catalonia. Rev. Esp. Cardiol. 2011, 11, 51-60.

13. Carrillo, X.; Fernandez-Nofrerias, E.; Rodriguez-Leor, O.; Oliveras, T.; Serra, J.; Mauri, J.; Curos, A.; Rueda, F.; García-García, C.; Tresserras, R.; et al. Early ST elevation myocardial infarction in non-capable percutaneous coronary intervention centres: In situ fibrinolysis vs. percutaneous coronary intervention transfer. Eur. Heart J. 2016, 37, 1034-1040. [CrossRef] [PubMed]

14. Gunnar, R.M.; Bourdillon, P.D.; Dixon, D.W.; Fuster, V.; Karp, R.B.; Kennedy, J.W.; Klocke, F.J.; Passamani, E.R.; Pitt, B.; Rapaport, E.; et al. ACC/AHA guidelines for the early management of patients with acute myocardial infarction. A report of the American College of Cardiology/American Heart Association Task Force on assessment of diagnostic and therapeutic cardiovascular procedures. Circulation 1990, 82, 664-707. [CrossRef] [PubMed]

15. Van de Werf, F.; Ardissino, D.; Betriu, A.; Cokkinos, D.V.; Falk, E.; Fox, K.A.; Julian, D.; Lengyel, M.; Neumann, F.J.; Ruzyllo, W.; et al. Management of acute myocardial infarction in patients presenting with ST-segment elevation. Task Force on the Management of Acute Myocardial Infarction of the European Society of Cardiology. Eur. Heart J. 2003, 24, 28-66. [CrossRef]

16. Steg, P.G.; James, S.K.; Atar, D.; Badano, L.P.; Blömstrom-Lundqvist, C.; Borger, M.A.; Di Mario, C.; Dickstein, K.; Ducrocq, G.; Fernandez-Aviles, F.; et al. ESC Guidelines for the management of acute myocardial infarction in patients presenting with ST-segment elevation: The Task Force on the management of ST-segment elevation acute myocardial infarction of the European Society of Cardiology. Eur. Heart J. 2012, 33, 2569-2619.

17. Ibañez, B.; James, S.; Agewall, S.; Antunes, M.J.; Bucciarelli-Ducci, C.; Bueno, H.; Caforio, A.L.P.; Crea, F.; Goudevenos, J.A.; Halvorsen, S.; et al. 2017 ESC Guidelines for the management of acute myocardial infarction in patients presenting with ST-segment elevation: The Task Force for the management of acute myocardial infarction in patients presenting with ST-segment elevation of the European Society of Cardiology (ESC). Eur. Heart J. 2018, 39, 119-177.

18. Ponikowski, P.; Voors, A.A.; Anker, S.D.; Bueno, H.; Cleland, J.G.F.; Coats, A.J.S.; Falk, V.; González-Juanatey, J.R.; Harjola, V.P.; Jankowska, E.A.; et al. 2016 ESC Guidelines for the diagnosis and treatment of acute and chronic heart failure: The Task Force for the diagnosis and treatment of acute and chronic heart failure of the European Society of Cardiology (ESC). Developed with the special contribution of the Heart Failure Association (HFA) of the ESC. Eur. Heart J. 2016, 37, 2129-2200.

19. Helgestad, O.K.L.; Josiassen, J.; Hassager, C.; Jensen, L.O.; Holmvang, L.; Sørensen, A.; Frydland, M.; Lassen, A.T.; Udesen, N.L.J.; Schmidt, H.; et al. Temporal trends in incidence and patient characteristics in cardiogenic shock following acute myocardial infarction from 2010 to 2017: A Danish cohort study. Eur. J. Heart Fail. 2019, 21, 1370-1378. [CrossRef]

20. Schrage, B.; Ibrahim, K.; Loehn, T.; Werner, N.; Sinning, J.M.; Pappalardo, F.; Pieri, M.; Skurk, C.; Lauten, A.; Landmesser, U.; et al. Impella Support for Acute Myocardial Infarction Complicated by Cardiogenic Shock. Circulation 2019, 139, 1249-1258. [CrossRef]

21. Wernly, B.; Seelmaier, C.; Leistner, D.; Stähli, B.E.; Pretsch, I.; Lichtenauer, M.; Jung, C.; Hoppe, U.C.; Landmesser, U.; Thiele, H.; et al. Mechanical circulatory support with Impella versus intra-aortic balloon pump or medical treatment in cardiogenic shock-a critical appraisal of current data. Clin. Res. Cardiol. 2019, 108, 1249-1257. [CrossRef] [PubMed] 
22. García-García, C.; Oliveras, T.; Rueda, F.; Pérez-Fernández, S.; Ferrer, M.; Serra, J.; Labata, C.; Vila, J.; Carrillo, X.; Rodríguez-Leor, O.; et al. Primary Ventricular Fibrillation in the Primary Percutaneous Coronary Intervention ST-Segment Elevation Myocardial Infarction Era (from the “Codi IAM" Multicenter Registry). Am. J. Cardiol. 2018, 122, 529-536. [CrossRef] [PubMed]

23. García-García, C.; Molina, L.; Subirana, I.; Sala, J.; Bruguera, J.; Arós, F.; Fiol, M.; Serra, J.; Marrugat, J.; Elosua, R. Sex-based differences in clinical features, management, and 28-day and 7-year prognosis of first acute myocardial infarction. RESCATE II study. Rev. Esp. Cardiol. (Engl. Ed.) 2014, 67, 28-35. [CrossRef] [PubMed]

24. Pöss, J.; Köster, J.; Fuernau, G.; Eitel, I.; de Waha, S.; Ouarrak, T.; Lassus, J.; Harjola, V.P.; Zeymer, U.; Thiele, H.; et al. Risk Stratification for Patients in Cardiogenic Shock After Acute Myocardial Infarction. IABP-SHOCK II. J. Am. Coll. Cardiol. 2017, 69, 1913-1920. [CrossRef]

25. Rivas-Lasarte, M.; Sans-Roselló, J.; Collado-Lledó, E.; García-Fernández, V.; Noriega, F.J.; Hernández-Pérez, F.J.; Fernández-Martínez, J.; Ariza, A.; Lidón, R.M.; Viana-Tejedor, A.; et al. External validation and comparison of the CardShock and IABP-SHOCK II risk scores in real-world cardiogenic shock patients. Eur. Heart J. Acute Cardiovasc. Care 2020, 2048872619895230. [CrossRef]

26. Rueda, F.; Borràs, E.; García-García, C.; Iborra-Egea, O.; Revuelta-López, E.; Harjola, V.P.; Cediel, G.; Lassus, J.; Tarvasmäki, T.; Mebazaa, A.; et al. Protein-based cardiogenic shock patient classifier. Eur. Heart J. 2019, 40, 2684-2694. [CrossRef]

27. Iborra-Egea, O.; Rueda, F.; Lakkisto, P.; Harjola, V.P.; García-García, C.; Bayes-Genis, A. Circulating MiRNA Dynamics in ST-Segment Elevation Myocardial Infarction-driven Cardiogenic Shock. Rev. Esp. Cardiol. (Engl. Ed.) 2019, 72, 783-786. [CrossRef]

28. Iborra-Egea, O.; Rueda, F.; García-García, C.; Borràs, E.; Sabidó, E.; Bayes-Genis, A. Molecular signature of cardiogenic shock. Eur. Heart J. 2019, ehz783. [CrossRef]

(C) 2020 by the authors. Licensee MDPI, Basel, Switzerland. This article is an open access article distributed under the terms and conditions of the Creative Commons Attribution (CC BY) license (http://creativecommons.org/licenses/by/4.0/). 